\title{
PALLET MOTION ON A MAGNETIC BRAKE ROLLER
}

\author{
IIdar SHARIFULLIN ${ }^{*}$, Andrey NOSKO* ${ }^{*}$, Eugene SAFRONOV* \\ *Faculty of Robotics and Complex Automation, Department of Lifting and Transport Systems, \\ Bauman Moscow State Technical University, 2-ya Baumanskaya 5/1, Moscow 105005, Russia \\ sharifullin@bmstu.ru, nosko@bmstu.ru, safronov@bmstu.ru
}

received 24 April 2021, revised 5 August 2021, accepted 24 September 2021

\begin{abstract}
The brake roller is one of the elements for the safe operation of gravity flow pallet racks. The brake roller of the magnetic (eddy current) type magnetic brake roller (MBR) is the most promising brake type. The working principle of the MBR is based on electromagnetic induction laws, according to which the braking of a conductor moving in the magnetic field is caused by the interaction of the conductor's eddy currents with the external magnetic field. In the paper, a mathematical model of the pallet motion on an MBR was developed. The equation of motion of the pallet on the MBR was derived. The calculation results were compared with the results of experimental studies of the pallet motion velocity on the MBR. For pallet speed under "drag peak" speed, the error of the mathematical model is $<7.7 \%$, and the error starts increasing once over the "drag peak" speed. Additional investigation of the coefficient of magnetic viscosity for speeds greater than the "drag peak" speed is required.
\end{abstract}

Key words: pallet, rack, gravity flow rack, magnetic brake roller, coefficient of magnetic viscosity

\section{INTRODUCTION}

A warehouse is a complex comprised of a building, pallet racks, transport and lifting devices for storage and internal processing of incoming items, from acceptance to processing before shipping an item to a customer. The finished product warehouse maintains enough stocks to enable continuity of shipments. In logistics, warehouses are used to improve throughput. The goal is to optimise goods movement, which can be achieved by optimising the space used [1], reducing the total distance travelled by forklifts [2] and using automated storage and search systems [3].

Improving the efficiency of using storage space with constant volume is a task relevant to any company. The task can be solved by block storage or deep-lane storage $[4,5]$. A pallet flow rack is one of such storage systems (Fig. 1) [6,7]. As noted in a previous paper [8], the pallet flow rack reduces the forklift travel distance by 22-25\% compared to single-deep racks.

A pallet flow rack can be subdivided into static and dynamic parts. The static element comprises standard rack elements providing stability in each direction and supports the dynamic elements. The dynamic part comprises a gravity flow rack and safety elements such as brake rollers and a stopping mechanism with a pallet separator [9].

Brake rollers are the main safety elements of gravity flow racks (GFRs) used in pallet racks for storing and moving pallets with cargo less than their own weight. The rollers are installed along the rack at a certain interval. Brake rollers are used to limit the speed of the pallet with cargo (further referred to simply as a pallet) [10]. In GFRs, centrifugal friction rollers are the most common. However, these rollers have many drawbacks, with the principal drawback being the wear of the brake friction lining, leading to changes in the roller braking characteristics.

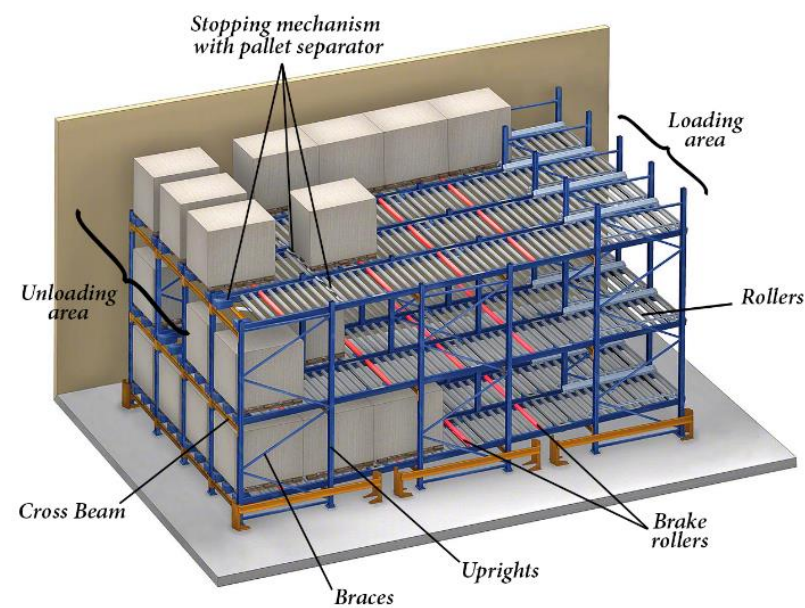

Fig. 1. Pallet flow rack

Analysis of different constructions of GFR brake rollers [11] revealed that magnetic (eddy current) brake rollers (MBRs) are the most promising brake roller type. Their main advantage is non-friction, contactless braking, meaning no wear of the roller brake lining.

The exploitation principle of such rollers is based on the laws of electromagnetic induction, whereby a conductor moving in the magnetic field is slowed down due to interaction between eddy currents in the brake conductor and the external magnetic field [12].

The paper aims to develop a mathematical model (further denoted as MM) of the pallet motion on an MBR and compare the results of experimental and analytical studies using this model. This paper reflects the Russian-language study of the authors [13]. 


\section{MBR CONSTRUCTION AND EXPLOITATION FEATURES}

Let us consider an MBR structure (Fig. 2) designed by the authors in Bauman Moscow State Technical University. The MBR comprises a brake insert 3 with a planetary multiplier 1 and an eddy current brake 2 installed on the insert axis 4 .

The braking process in the MBR (Fig. 3 ) begins with torque transmission to the roller case (body of the brake insert 3 ). Then the torque is transmitted to a disc 5 (transparent display) via the multiplier. The disc starts moving in the magnetic field created by permanent magnets placed with alternating polarity and rigidly connected to the brake insert via an adaptor.

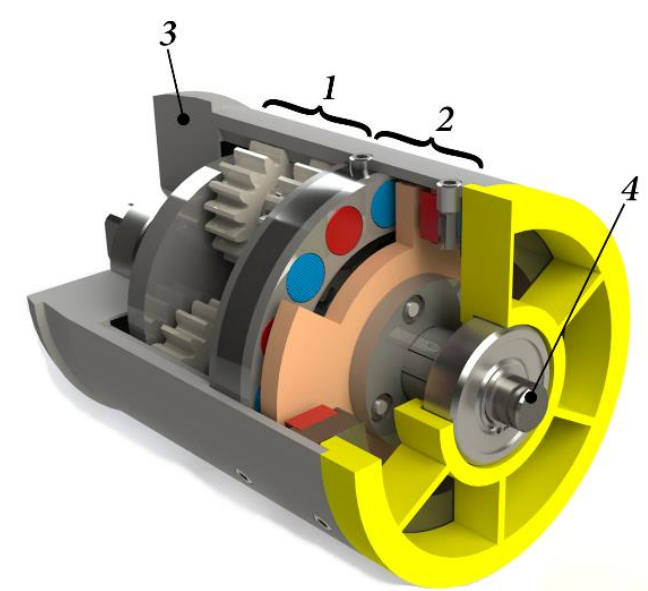

Fig. 2. General view of MBR (3D model in SolidWorks): 1 - planetary multiplier; 2 - magnetic (eddy current) brake; 3 - brake insert; 4 - axis. MBR, magnetic brake roller

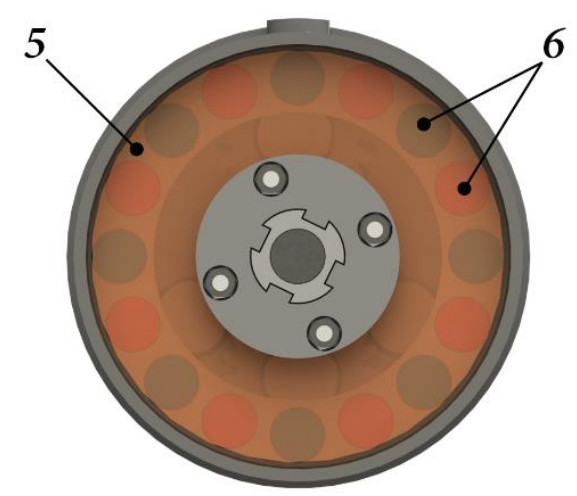

Fig. 3. Magnetic (eddy current) brake: 5 - disc (represented by transparent display), 6 - permanent magnets

Disc 5 is made of material with high specific conductivity, such as a copper or aluminium alloy. According to Lorentz law, eddy currents are generated on the disc surface, and a braking torque proportional to the external load (braking torque) is generated. Permanent magnets are made of Nd-Fe-B alloy. Such magnets have the best magnetic and electrical properties and enjoy a service life of $\geq 20-25$ years. Moreover, they have high coercive force, making MBRs almost immune to external magnetic fields [14].

In an MBR, the size of the air gap between the magnets 6 and the disc 5 is constant, while the braking torque is a function of their relative rotation speed.

\section{MATHEMATICAL MODEL OF MBR}

For developing the MM, the approaches used for centrifugal friction rollers [10, 15] and eddy current braking devices [16,17] were utilised. Fig. 4 shows the calculation diagrams of the GFR and BMR.
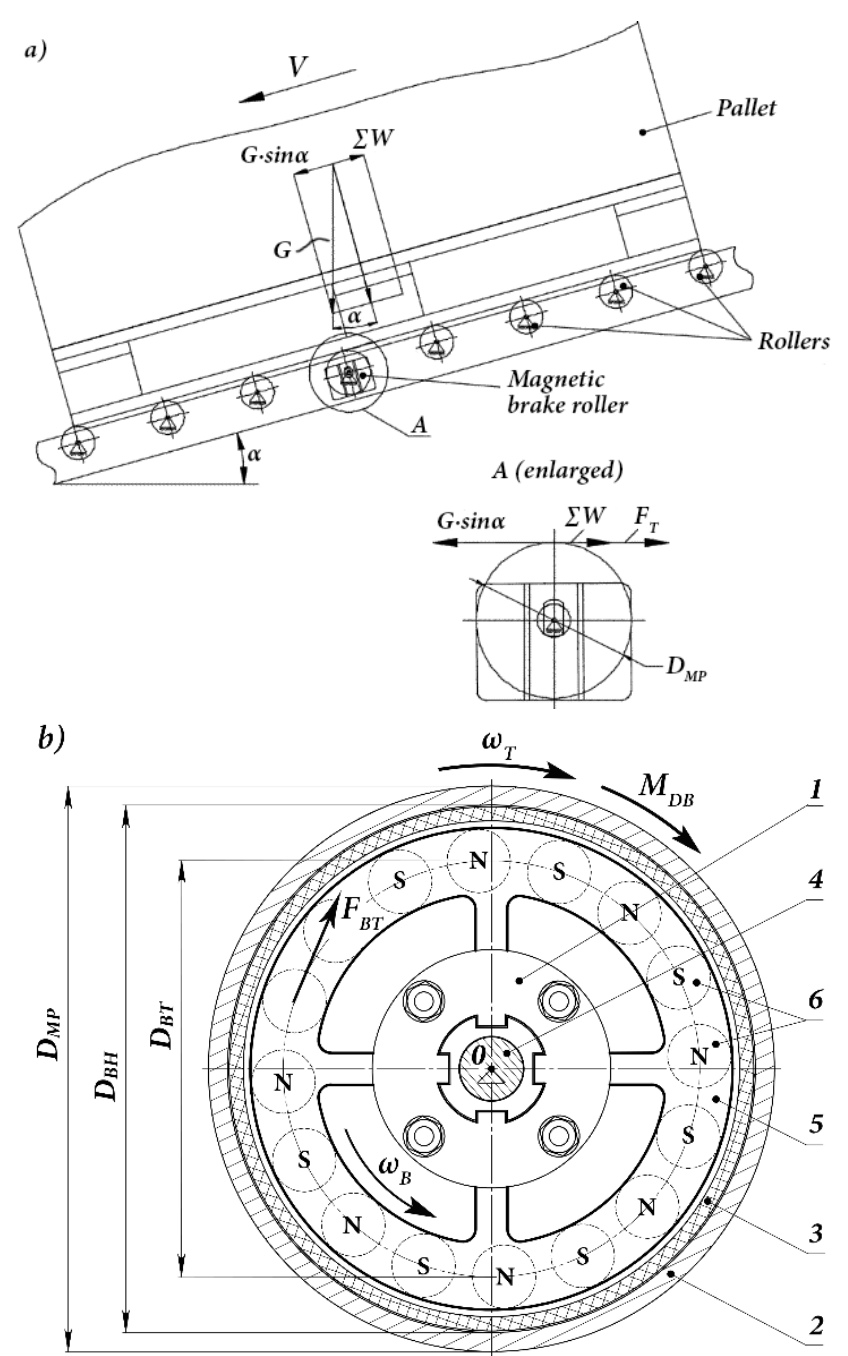

Fig. 4. Design schemes of (a) GFR and (b) MBR: 1 - a hub; 2 - shell MBR; 3 - brake insert; 4 - fixed axis of the brake insert; 5 copper disc; 6 - permanent magnets. GFR, gravity flow rack; MBR, magnetic brake roller.

The main equation of motion governing the movement of the pallet on the MBR (Fig. 4a) is given by

$M \frac{d V}{d t}=G \cdot \sin \alpha-\sum W-F_{T}=G \cdot(\tan \alpha-w)-F_{T}$,

where $M$ is the pallet mass, in kilograms; $V$ is the pallet speed, in metres per second; $G$ is the force of gravity acting on the pallet, in newtons; $\sum W$ is the sum of forces resisting the pallet motion on the GFR, in newtons; $F_{T}$ is the MBR breaking force, in newtons; $w=\sum \frac{W}{G \cdot \cos \alpha}$ is the equivalent coefficient of resistance to pallet motion on a GFR [18]. As the GFR slope angle is small $\left(\alpha=1.7 \ldots 2.8^{\circ}\right)$, one can assume that $\cos \alpha \cong 1$.

In its turn, the MBR rotation can be described by the main equation of rotary dynamics relative to the point $O$ (Fig. $4 b$ ): 
$J_{M P} \frac{d \omega_{T}}{d t}=\sum M_{O}=M_{D B}-M_{T 1}-M_{T 2}$

where $J_{M P}$ is the MBR moment of inertia, in kilogram metre squared; $\omega_{T}$ is the MBR angular velocity, in radians per second; $M_{D B}$ is the drive torque acting on the MBR case, in newtonmetres; $M_{T 1}$ and $M_{T 2}$ are the braking torques acting on the body and nave of the eddy current brake of the MBR reduced to its body, accordingly, in newton-metres.

Assuming that the pallet motion on the MBR is in the steady state $\left(\frac{d V}{d t}=0\right)$ and the pallet speed is $V=\frac{\omega_{T} \cdot D_{M P}}{2}$, where $D_{M P}$ is the MBR diameter, we get

$\frac{d V}{d t}=\frac{d\left(\frac{\omega_{T} \cdot D_{M P}}{2}\right)}{d t}=0 ; J_{M P} \frac{d \omega_{T}}{d t}=0 ; M_{D B}-M_{T 1}-M_{T 2}=0$.

Thus, the MM of the pallet movement of the MBR can be represented as follows:

$M_{D B}=M_{T 1}+M_{T 2}$.

As the GFR slope angle $\alpha$ is small, the drive torque $M_{D B}$ acting on the MBR body is equal to

$M \frac{d V}{d t}=0 ; F_{T}=G(\tan \alpha-w) ; M_{D B}=\frac{D_{M P} \cdot G \cdot(\tan \alpha-w)}{2}$

According to a previous study [15], the following assumption can be made for calculating the sum of forces $\sum W$ resisting the pallet motion on the GFR:

- there is no sliding of the pallet on the rollers;

- the movement of the pallet on the GFR is uniform, so the forces of inertia of the carrier rollers and pallet reach zero;

- the resistance caused by the GFR surface's unevenness is local and can be omitted in the calculations.

In this case, one should only consider the friction resistance in the supports of the carrier rollers and the rolling friction resistance of the GFR carrier rollers. The calculation of these factors is thoroughly described in [19-21].

The braking torque $M_{T 1}$ acting on the MBR case is given by

$M_{T 1}=F_{B T} \cdot \frac{D_{B T}}{2}$,

where $F_{B T}$ is the braking force of the eddy current brake (in newtons); $D_{B T} / 2$ is the distance from the MBR rotation axis to the centre of the permanent magnets (in metres).

The braking torque $M_{T 2}$ acting on Nave 1 of the eddy current brake of the MBR reduced to its body is given by the following expression:

$M_{T 2}=F_{B T} \cdot \frac{D_{B T}}{2} \cdot u \cdot \eta_{M P}$

where $u$ is the gear ratio of the MBR multiplier and $\eta_{M P}$ is the MBR efficiency.

By substituting Eqs (5)-(7) in Eq. (4), we get

$\frac{D_{M P} \cdot G \cdot(\tan \alpha-w)}{2}=F_{B T} \cdot \frac{D_{B T}}{2}+F_{B T} \cdot \frac{D_{B T}}{2} \cdot u \cdot \eta_{M P}$.

Given that $G=M \cdot g$ (where $g=9.81 \mathrm{~m} / \mathrm{s} 2$ is the acceleration due to gravity), the braking force of the MBR eddy current brake is given by

$F_{B T}=\frac{D_{M P} \cdot M \cdot g \cdot(\tan \alpha-w)}{D_{B T} \cdot\left(1+u \cdot \eta_{M P}\right)}$.
On the other hand, according to $[16,17,22-29]$ the braking force of the eddy current brake is given by

$F_{B T}=\beta \cdot \omega_{\text {rel }} \cdot \frac{D_{B T}}{2}$,

where $\beta$ is the coefficient of magnetic viscosity (in newton-second per metre); $\omega_{\text {rel }}$ is the angular velocity of the copper disc relative to the permanent magnets (in units per second).

So, for the considered MBR construction (Fig. 4b), $\omega_{\text {rel }}=$ $\omega_{T}+\omega_{B}$, where $\omega_{T}=\pi \cdot n_{T} / 30$ is the angular velocity of the MBR body (units per second); $n_{T}$ is the rotation speed of the MBR body (in revolutions per minute); $\omega_{B}=\pi \cdot n_{B} / 30$ is the angular velocity of the eddy current brake nave (units per second); $n_{B}$ is the rotation speed of the eddy current brake body (in revolutions per minute). Because of the multiplier, $n_{B}=u \cdot n_{T}$.

As there is no slip between the pallet and the MBR (based on the studies conducted in $[10,15])$, the MBR body rotation speed $n_{T}$ is

$n_{T}=\frac{60 \cdot V}{\pi \cdot D_{M P}}$.

So, $\omega_{\text {rel }}$ can be represented as follows:

$\omega_{\text {rel }}=\frac{\pi}{30}\left(u \cdot n_{T}+n_{T}\right)=\frac{2 \cdot V}{D_{M P}}(1+u)$.

By substituting Eq. (12) in Eq. (10) and equalising Eqs (9) and (10), we get a formula for calculating the speed $V$ of pallet motion on the MBR:

$V=\frac{D_{M P}^{2} \cdot g \cdot(\tan \alpha-w)}{D_{B T}^{2} \cdot \beta \cdot\left(1+u \cdot \eta_{M P}\right)(1+u)} M$.

By analysing Eq. (13), one can see that the coefficient of magnetic viscosity $\beta$ and the gear ratio $u$ are the main parameters defining the MBR braking capacity and, consequently, the speed of the pallet motion on the MBR. However, analysis of the influence of the gear ratio $u$ will be carried out in further studies. In the proposed paper for the developed MBR design, it is possible to change the efficiency only by changing the number of magnets and the gap, thereby changing only the coefficient of magnetic viscosity $\beta$.

\section{COEFFICIENT OF MAGNETIC VISCOSITY}

According to [16, 17, 22, 23], the coefficient of magnetic viscosity is given by

$\beta_{1}=\frac{\pi \cdot \sigma}{4} D^{2} d B^{2}$

$\beta=n \cdot \beta_{1}$,

where $\beta_{1}$ is the coefficient of magnetic viscosity for one magnet; $n$ is the number of magnets; $\sigma$ is the specific conductivity of the conductive body material (copper disc, Fig. 3), in siemens per metre; $B$ is the magnetic induction, in teslas; $D$ is the magnet cross-sectional diameter, in metres; $d$ is the thickness of the conducting body (copper disc), in metres.

However, Eq. (14) does not consider the influence of the air gap between the copper disc and the magnets and their relative position (edge effect) on the coefficient of magnetic viscosity $\beta$ and the braking force $F_{B T}$.

In this case, the coefficient of magnetic viscosity $\beta$ is a com- 
plex indicator governed by many parameters. It is hard to establish the theoretical relationships linking these parameters, so it is hard to make a justified choice of the structural parameters of the eddy current brake of the MBR.

Because of this fact, experimental studies were conducted in [30] to determine the coefficient of magnetic viscosity for one magnet, $\beta_{1}$, under the operational condition of an MBR in a GFR. The following facts about the coefficient of magnetic viscosity $\beta_{1}$ were established:

- The coefficient decreases if the air gap between the conductive body and permanent magnets increases, and this relationship is exponential.

- The coefficient decreases if the rotation speed of the conductive body increases.

- The coefficient is invariant with the distance between the centres of the conductive body and the permanent magnet.

- The coefficient is reduced by the "edge effect" related to the air gap.

Considering the experimental studies on the coefficient of magnetic viscosity $\beta_{1}$, the MBR shown in Fig. 2 was designed to ensure high brake torque for the operational conditions characteristic for GFR. Formula (13) can be rewritten as follows:

$V=\frac{D_{M P}^{2} \cdot g \cdot(\tan \alpha-w)}{D_{B T}^{2} \cdot \beta_{1} \cdot n \cdot\left(1+u \cdot \eta_{M P}\right)(1+u)} M$.

\section{COMPARISON OF CALCULATED AND EXPERIMENTAL RELATIONSHIP OF THE VELOCITY OF PALLET MOVEMENT ON THE MBR}

Experimental investigations of the MBR were conducted for $n=8$ and $n=16$ permanent magnets on an experimental stand that allows simulating real operating modes of brake rollers of various designs used in the GFR for pallets [30]. Generally, the MBR diameter $D_{M P}$ is chosen based on the structural constraints of the GFR and the gravity rack for pallets. In practice, tubes with diameter $D_{M P}$ of $80 \mathrm{~mm}$ or $89 \mathrm{~mm}$ and wall thickness of $3 \mathrm{~mm}$ are the most common. In the developed construction (Fig. 2), $D_{M P}=89 \mathrm{~mm}$ and $D_{B H}=83 \mathrm{~mm}$, and a two-stage multiplier with a gear ratio of 24 is used based on the analysis conducted in [31]. The efficiency $\eta_{M P}$ of MBR can be calculated similarly to that of the centrifugal friction roller $[10,15]$. In this case, according to experimental data [30], the coefficient of magnetic viscosity is $\beta_{1}=0.113 \mathrm{~N} \mathrm{~s} / \mathrm{m}$ for the considered MBR construction (Fig. 2). Initial data for calculating the speed $V$ of the pallet movement on MBR are shown in Tab.1.

Tab. 1. Initial data for calculating the speed $V$ of the pallet movement on MBR

\begin{tabular}{|c|c|c|}
\hline Parameter & Value & Unit \\
\hline Pallet mass, $M$ & $100 \div 1,000$ & $\mathrm{~kg}$ \\
\hline MBR diameter, $D_{M P}$ & 0.089 & $\mathrm{~m}$ \\
\hline MBR length, $L_{M P}$ & 0.88 & $\mathrm{~m}$ \\
\hline $\begin{array}{c}\text { Distance from the MBR rotation axis } \\
\text { to the centre of permanent magnets } \\
D_{B T} / 2\end{array}$ & 0.03 & $\mathrm{~m}$ \\
\hline \begin{tabular}{c} 
Coefficient of magnetic viscosity, $\beta_{1}$ \\
\hline
\end{tabular} & 0.113 & $\mathrm{~N} \cdot \mathrm{s} / \mathrm{m}$ \\
\hline
\end{tabular}

\begin{tabular}{|c|c|c|}
\hline $\begin{array}{c}\text { Equivalent coefficient of resistance to } \\
\text { the pallet motion on the GFR sur- } \\
\text { face, } w\end{array}$ & 0.02 & - \\
\hline GFR slope angle, $\tan \alpha$ & 0.04 & - \\
\hline
\end{tabular}

GFR, gravity flow rack; MBR, magnetic brake roller.

The percentage error of the theoretical calculation is given by

$\varepsilon=\frac{\left|V_{C a l c}-\widetilde{V}_{E x p}\right|}{\widetilde{V}_{E x p}} 100$,

where $V_{\text {Calc }}$ is the calculated speed of pallet motion on the MBR, in metres per second; $\tilde{V}_{E x p}$ is the average experimentally measured value of the pallet speed, in metres per second.

The results and a comparative analysis of the obtained calculation and experimental results of the investigation of the pallet speed $V$ of motion on the MBR are shown in Tabs 2 and 3 and Fig. 5.

Tab. 2. Results of the calculated and experimental studies of the speed $V$ (metres per second) of the pallet movement along the MBR

\begin{tabular}{|c|c|c|c|c|}
\hline \multirow{2}{*}{$\begin{array}{c}\text { Pallet } \\
\text { mass } \boldsymbol{M} \text {, }\end{array}$} & \multicolumn{4}{|c|}{ Number of magnets, $\boldsymbol{n}$} \\
\cline { 2 - 5 } & \multicolumn{2}{|c|}{ Calculation } & \multicolumn{2}{c|}{ Experiment } \\
\cline { 2 - 5 } & 8 & 16 & 8 & 16 \\
\hline 100 & 0.102 & 0.051 & 0.109 & 0.049 \\
\hline 200 & 0.204 & 0.102 & 0.220 & 0.096 \\
\hline 300 & 0.305 & 0.153 & 0.330 & 0.143 \\
\hline 400 & 0.407 & 0.204 & 0.473 & 0.195 \\
\hline 500 & 0.509 & 0.255 & 0.630 & 0.252 \\
\hline 600 & 0.611 & 0.305 & 0.795 & 0.308 \\
\hline 700 & - & 0.356 & - & 0.389 \\
\hline 800 & - & 0.407 & - & 0.480 \\
\hline 900 & - & 0.458 & - & 0.585 \\
\hline 1,000 & - & 0.509 & - & 0.687 \\
\hline
\end{tabular}

MBR, magnetic brake roller

Tab. 3. Comparative analysis of the results of calculated and experimental studies of the speed $V$ of the pallet movement along the MBR

\begin{tabular}{|c|c|c|}
\hline \multirow{2}{*}{ Pallet mass $\boldsymbol{M}, \mathbf{k g}$} & \multicolumn{2}{|c|}{ Simulation error, \% } \\
\cline { 2 - 3 } & 8 & 16 \\
\hline & 7.3 & 3.3 \\
\hline 100 & 7.7 & 6.2 \\
\hline 200 & 7.7 & 6.8 \\
\hline 300 & 13.9 & 4.4 \\
\hline 400 & 19.2 & 1.2 \\
\hline 500 & 23.1 & 0.8 \\
\hline 600 & - & 8.5 \\
\hline 700 & - & 15.2 \\
\hline 800 & - & 21.6 \\
\hline 900 & - & 25.8 \\
\hline 1,000 & & \\
\hline
\end{tabular}

MBR, magnetic brake roller 


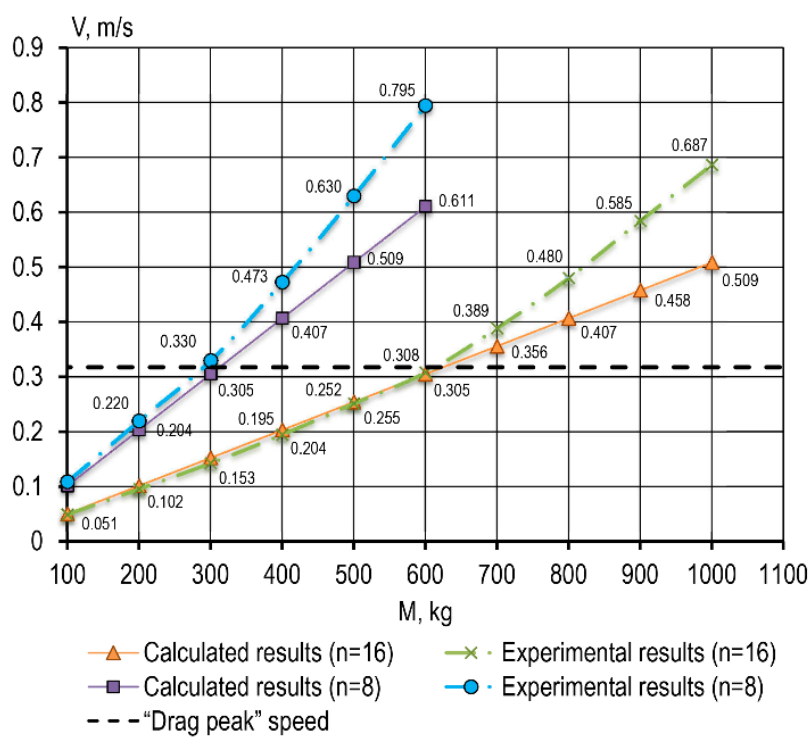

Fig. 5. Comparative analysis of the results of calculated and experimental studies of the speed $\mathrm{V}$ of pallet movement along the MBR with different numbers of permanent magnets $n$. MBR, magnetic brake roller

The comparison of experiments and calculations revealed that the error of the MM increases as the velocity of a pallet with mass $M$ increases. The error is related to the assumption that the eddy current brake MBR is a linear viscous friction element [16, 17, 22, 23]. So, the calculated pallet speed is almost linear, as seen very well from Fig. 5. However, based on the results of multiple studies [32], one has to take into account the "drag peak" speed parameter given by the following expression:

$\omega_{o t n}=\frac{4}{\mu \cdot \sigma \cdot d \cdot D_{B T}}$,

where $d$ is the thickness of the conducting body (copper disc, Fig. 3 ), in metres; $\mu$ is the magnetic permeability of the conductive body material, in henries per metre.

"Drag peak" speed is the angular velocity of a conducting body (copper disc) relative to permanent magnets over which the eddy currents generated on the conducting body surface do not reach their limit value, leading to reduced magnetic viscosity $\beta$ and, consequently, reduced braking torque on an MBR.

By equalising Eqs. (12) and (18), we obtain a formula for calculating the pallet speed $[V]$ of motion on an MBR when the copper disc reaches the "drag peak" speed:

$\left[V_{p k}\right]=\frac{2 \cdot D_{M P}}{\mu \cdot \sigma \cdot d \cdot D_{B T}(1+u)}$

As seen from Fig. 5, the experimental velocity plots change their slope angle, while the difference between the calculated and experimental results starts increasing after the intersection with the "drag peak" speed line.

\section{SUMMARY}

A MM of the pallet motion on an MBR was developed. An equation of the pallet motion on an MBR was derived.

The results of simulation and experimental studies of the pallet velocity moving on an MBR were compared. For pallet speed less than $\left[V_{p k}\right]$, the error of the $\mathrm{MM}$ is $<7.7 \%$, and the error starts increasing once exceeding $\left[V_{p k}\right]$.

Additional investigation of the coefficient of magnetic viscosity $\beta_{1}$ for speeds greater than the "drag peak" speed is required.

\section{REFERENCES}

1. Derhami S, Smith JS, Gue KR. Optimising space utilisation in block stacking warehouses. Int J Of Prod Res. 2017; 55(21):6436-6452.

2. Ghalehkhondabi I. Masel DT. Storage allocation in a warehouse based on the forklifts fleet availability. Journal Of Algorithms \& Computational Technology. 2018; 12(2):127-135.

3. Heragu SS, Cai X, Krishnamurthy A, Malmborg CJ. Analytical models for analysis of automated warehouse material handling systems. Int $J$ Of Prod Res. 2011; 49(22);6833-6861.

4. Sulirova I, Zavodska L, Rakyta M, Pelantova V. State-of-the-art approaches to material transportation handling and warehousing. 12th International scientific conference of young scientists on sustainable modern and safe transport. Procedia Engineering. 2017; 192:857-862.

5. Boywitz D, Boysen N. Robust storage assignment in stack- and queue-based storage systems. Computers \& Operations Research. 2018; 100:189-200

6. Accorsi R, Baruffaldi G, Manzini R. Design and manage deep lane storage system layout. An iterative decision-support model. Int J Adv Manuf Technol. 2017; 92(1-4):57-67.

7. Eo J, Sonico J, Su A, Wang W, Zhou C, Zhu Y, Wu S, Chokshi T. Structured comparison of pallet racks and gravity flow racks. IIE Annual Conference and Expo. 2015; 1971-1980.

8. Wu S, Wu Ya, Wang Ya. A structured comparison study on storage racks system. Journal of Residuals Science \& Technology. 2016; 13(8).

9. Vujanac R, Miloradovic N, Vulovic S. Dynamic storage systems ANNALS of Faculty Engineering Hunedoara - International Journal of Engineering. 2016; XIV:79-82.

10. Safronov E, Nosko A. A Method to Determine Allowable Speed for a Unit Load in a Pallet Flow Rack. Acta Mechanica et Automatica 2019; 13(2):80-85.

11. Safronov E, Sharifullin I, Nosko A. Ustroystva bezopasnoy ekspluatatsii gravitatsionnykh rolikovykh konveyyerov palletnogo tipa: Monografiya [Devices for safe operation of pallet type gravity roller conveyors: Monograph] Universitetskaya kniga Moscow (in Russian). 2018.

12. Kamenskaya NI, Sein VA, Zvereva Ml. A Study of the Causes of Failure of Permanent Magnets from Cast Hard Magnetic Alloys Metal. Science and Heat Treatment. 2017; 59:232-236.

13. Sharifullin I, Nosko A, Safronov E. Matematicheskaya model' protsessa dvizheniya pallety po tormoznomu roliku magnitnogo tipa [Mathematical model of the motion pallet process on brake magnetic type roller]. The Russian Automobile and Highway Industry Journal. 2020; 17(3):364-373 (in Russian).

14. Ozolin AU, Skubov DU, Shtukin LV. Sposoby tormozheniya padayushchego lifta s pomoshch'yu postoyannykh magnitov [Methods of braking a falling elevator with the help of permanent magnets] Nauchno-tekhnicheskiye vedomosti Sankt-Peterburgskogo gosudarstvennogo politekhnicheskogo universiteta 2008; 6(70):82-86 (in Russian)

15. Safronov $E$, Nosko A. Influence of the brake lining position on the efficiency of the centrifugal friction roller. IOP Conference Series: Materials Science and Engineering. 2020: 709(2).

16. Simeu E, Georges D. Modeling and control of an eddy current brake. Control Engineering Practise. 1996; 14(1):19-26.

17. Ozolin AU, Skubov DU, Shtukin LV. Issledovaniye vikhretokovogo diskovogo tormoza [Research eddy current disc brake]. Nauchnotekhnicheskiye vedomosti Sankt-Peterburgskogo gosudarstvennogo politekhnicheskogo universiteta. 2009: 1(74):57-60 (in Russian). 
18. Luskan' OA. Opredeleniye skorosti transportirovaniya shtuchnykh gruzov na inertsionnom rolikovom konveyyer [Determining the speed of transportation of piece goods on an inertial roller conveyor]. Izv TuIGU Pod"yemno-transportnyye mashiny i oborudovaniye. 2003; 4:84-89 (in Russian).

19. Zenkov RL, Ivashkov II, Kolobov LN. Mashiny nepreryvnogo transporta [Continuous transport machines]. Moscow (in Russian). 1997.

20. Luskan' OA. Teoreticheskiye osnovy peremeshcheniya gruzov impul'snymi konveyyerami [Theoretical Foundations of the Movement of Goods by Pulse Conveyors]. Saratov (in Russian). 2010.

21. Luskan' OA. Inzhenernyy raschet impul'snykh konveyyerov [Engineering calculation of pulse conveyors]. Saratov (in Russian). 2011.

22. Hollowell TC, Kahl JT, Stanczak MD, Wang Y. Eddy Current Brake Design for Operation with Extreme Back-drivable Eddy Current Motor. Mechanical Engineering Undergraduates. 2010.

23. Andrew HC, Hayward V. Eddy Current Brakes for Haptic Interfaces: Design Identification and Control. IEEE/ASME Transactions on Mechatronics. 2008; 13(6):669-677.

24. Kerem K, Afzal S, Park EJ. Analytical modeling of eddy current brakes with the application of the time varying magnetic fields. Applied Mathematical Modeling. 2015; 1168-1179.

25. Kerem K, Park EJ, Afzal S. Improved braking torque generation capacity of an eddy current brake with time varying magnetic fields: A numerical study. Finite Elements in Analysis and Design. 2012; 59:66-75

26. Lee K, Park K. Modeling eddy currents with boundary conditions by sing Coulomb's law and the method of images. IEEE Transactions on Magnetics. 2002; 38(2):1333-1340.
27. Heald MA. Magnetic braking: Improved theory. American Journal of Physics. 1988; 56(6):521-522.

28. Anwar S. A parametric model of an eddy current electric machine for automotive braking applications. IEEE Transactions on Control Systems Technology. 2002; 12(13):422-427.

29. Shin HJ, Choi JY, Cho HW, Jang SM. Analytical torque calculations and Experimental testing of permanent magnet Axial eddy current brake. IEEE Transactions of Magnetics. 2013; 49(7):4152-4155.

30. Sharifullin I, Nosko A, Safronov E, Kirillov D. Experimental study of eddy current braking applicable to gravity roller conveyor. Fundamental and Applied Problems of Engineering and Technology. 2020; 342(4-1):106-116.

31. Ghomri L, Sari Z. Mathematical modeling of the average retrieval time for flow-rack automated storage and retrieval systems. J Manuf Syst. 2017; 44:165-178.

32. Thompson MT. Permanent magnet electrodynamic brakes design principles and scaling laws. Online Symposium for Electrical Engineers. 2009.

Ildar Sharifullin: (D) https://orcid.org/0000-0002-1930-2602

Andrey Nosko: (D) https://orcid.org/0000-0003-1382-4095

Eugene Safronov: (iD https://orcid.org/0000-0002-4250-7147 